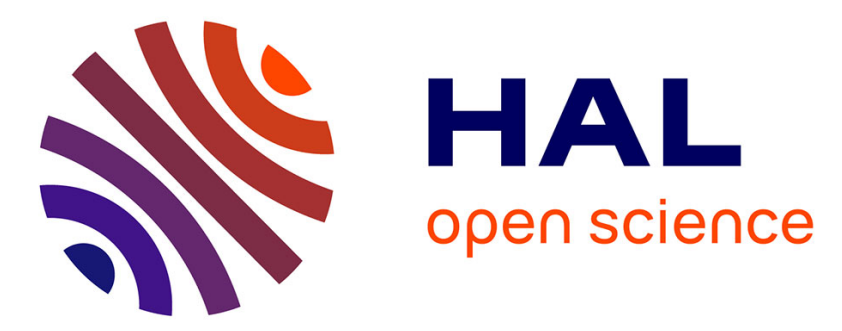

\title{
HHT-Based Artificial Seismic Accelerograms Generation
}

Eleni Vrochidou, Petros Alvanitopoulos, Ioannis Andreadis, Anaxagoras

Elenas, Katerina Mallousi

\section{To cite this version:}

Eleni Vrochidou, Petros Alvanitopoulos, Ioannis Andreadis, Anaxagoras Elenas, Katerina Mallousi. HHT-Based Artificial Seismic Accelerograms Generation. 10th IFIP International Conference on Artificial Intelligence Applications and Innovations (AIAI), Sep 2014, Rhodes, Greece. pp.476-486, 10.1007/978-3-662-44654-6_47 . hal-01391349

\section{HAL Id: hal-01391349 \\ https://inria.hal.science/hal-01391349}

Submitted on 3 Nov 2016

HAL is a multi-disciplinary open access archive for the deposit and dissemination of scientific research documents, whether they are published or not. The documents may come from teaching and research institutions in France or abroad, or from public or private research centers.
L'archive ouverte pluridisciplinaire HAL, est destinée au dépôt et à la diffusion de documents scientifiques de niveau recherche, publiés ou non, émanant des établissements d'enseignement et de recherche français ou étrangers, des laboratoires publics ou privés. 


\title{
HHT-Based Artificial Seismic Accelerograms Generation
}

\author{
Eleni Vrochidou ${ }^{1}$, Petros Alvanitopoulos ${ }^{2}$, Ioannis Andreadis ${ }^{3}$, Anaxagoras Elenas ${ }^{4}$ \\ and Katerina Mallousi ${ }^{5}$ \\ 1,2,3,5 Department of Electrical and Computer Engineering, Democritus University of Thrace, \\ GR-67100 Xanthi, Greece \\ ${ }^{4}$ Department of Civil Engineering, Democritus University of Thrace, GR-67100 Xanthi, \\ Greece
}

\begin{abstract}
A new efficient approach for generating spectrum-compatible seismic accelerograms is proposed. It is based on the Hilbert-Huang Transform (HHT); one natural seismic accelerogram is decomposed into frequency and amplitude components. The components are appropriately modified to synthesize the artificial seismic accelerogram that appears to have compatible acceleration spectrum with the natural seismic accelerogram. The HHT is an adaptive signal processing technique for analyzing nonlinear and non-stationary data such as seismic accelerograms. With HHT a seismic accelerogram is decomposed into a finite and small set of components. These components have well defined instantaneous frequencies, estimated by the first derivative of the phase of the analytic signal. The method is tested using twenty natural seismic records and a comparison with two established methodologies is provided.
\end{abstract}

Keywords: Hilbert-Huang Transform, artificial spectrum-compatible seismic accelerograms, frequency components.

\section{Introduction}

Earthquake engineering is the scientific field concerned with the study of the behavior of structures subject to seismic loading. Earthquake accelerograms (seismic signals) are required in order to simulate the response of structures. Disaster scenarios need an extensive set of seismic signals and although a large database of recordings of seismic excitations exists, for many regions there is lack of actual acceleration time-history records [1]. Artificial spectrum-compatible accelerograms are widely used in the dynamic analysis of structures. The proposed method is based on HHT for generating spectrum-compatible earthquake accelerograms. It is well-known that the HHT is an appropriate signal processing technique for analyzing non-stationary and nonlinear signals such as seismic signals $[2,3]$.

The HHT decomposes the earthquake accelerogram into a finite number of Intrinsic Mode Functions (IMFs), and provides an energy-frequency-time distribution, the 
Hilbert spectrum. The extraction of the IMFs is based on the local characteristics of the seismic signal and not on a priori assumptions. Unlike traditional signal processing techniques, in HHT the frequency is defined through differentiation and there is no uncertainty principle limitation on time or frequency resolution from the convolution pairs based on a priori bases. Thus, HHT provides sharper energy-frequency-time distribution [2]. Moreover, the finite number of the extracted IMFs is adequate to describe any seismic signal and therefore reduces the computational burden of the algorithm.

Previously reported methods in the literature employ HHT to generate spectrumcompatible accelerograms $[4,5]$. In method [4] six natural records are required to describe the high and low frequency areas of the target design spectrum. The artificial spectrum-compatible seismic signal is obtained by solving an optimization problem. The difference between the target spectrum and the response spectrum of the artificially generated seismic signal is treated as the cost function. In contrast to the aforementioned method, in the proposed technique only one initial earthquake signal is required. Moreover, it can be of any intensity and thus no limitations are imposed. Another method is proposed in [5].Artificial seismic signals are generated and submitted to a correlation study. The correlation study demonstrates that the artificially generated seismic signals share similar seismic parameter values to those of natural accelerograms.

The proposed methodology is applied to twenty natural seismic accelerograms. In order to reveal the effectiveness of the proposed method, a comparison with two wellestablished algorithms for generating spectrum-compatible accelerograms is presented. The first is Gasparini and Vanmarcke algorithm [6] implemented by SIMQKE software [7]. The second is Hallodorson and Papageorgiou algorithm [8] implemented by SeismoArtif artificial earthquake accelerograms generator [9]. Results demonstrate that the proposed method is as reliable as the methodologies implemented by the two established Computer-Aided Design (CAD) tools.

\section{The Hilbert-Huang Transform}

The HHT was introduced by Huang et al [2] and comprises two parts: the Empirical Mode Decomposition (EMD) and the Hilbert Spectral Analysis (HSA).

\subsection{Empirical Mode Decomposition (EMD)}

The EMD can decompose complex data into a finite and small number of IMFs. The method is considered to be valid as it is an adaptive method and since the decomposition is based on the local characteristics of the signal, it is appropriate for nonstationary and non-linear signals $[2,3]$. The decomposition process for a seismic signal is described in Figure $1[2,3]$. 


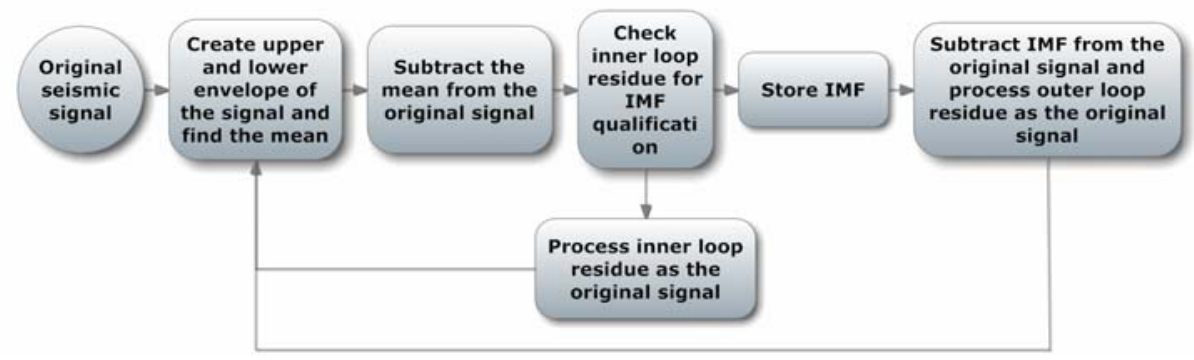

Fig. 1. Flow chart of the EMD.

\subsection{Hilbert Spectral Analysis (HSA)}

The HSA applies the Hilbert Transform to each IMF so as to obtain the instantaneous frequency data and construct the energy-frequency-time distribution. For all $c_{j}(t)$ components, the Hilbert Transform $y_{j}(t)$ is:

$$
y_{j}(t)=\frac{1}{\pi} P \int_{-\infty}^{+\infty} \frac{c_{j}(\tau)}{t-\tau} d \tau
$$

where P denotes the Cauchy Principal Value. The IMF components are defined by the equation:

$$
c_{j}(t)=\operatorname{Re}\left(a_{j}(t) e^{i \theta_{j}(t)}\right)=a_{j}(t) \cos \theta_{j}(t)
$$

where $\operatorname{Re}()$ is the real part. The initial signal is then written as:

$$
X(t)=\operatorname{Re}\left(\sum_{j=1}^{n} a_{j}(t) \cos \left(\int 2 \pi f_{j}(t) d t\right)\right)
$$

The residue $r_{n}(t)$ is not included to the above equation because it is either a monotonic function or a constant. Equation (3) shows that the amplitude and frequency can be expressed as functions of time and can strengthen the time-frequency distribution of the amplitude. This distribution $\mathrm{H}(\omega, \mathrm{t})$ is called the Hilbert spectrum.

\section{$3 \quad$ Response Spectrum and Strong Motion Duration}

\subsection{Response Spectrum}

The response spectrum is an essential tool in earthquake engineering and is the plot of the peak response acceleration, displacement or velocity of a single-degree-of- 
freedom oscillator in dependence of its fundamental period under the same seismic excitation. Figure 2 demonstrates the concept of the earthquake response spectrum.

\subsection{Strong Motion Duration (SMD)}

A major issue of the spline fitting arises at the boundaries since cubic splines have wide swings if they are left unattended [2]. To eliminate end effects, only the strong motion duration of the seismic excitation is considered in the proposed methodology. The strong motion duration (SMD) is the time of the earthquake where the most seismic energy is released. The SMD after Trifunac/Brady [10] is defined as time elapsed between $5 \%$ and $95 \%$ of the Husid diagram [11] and is defined as follows:

$$
\mathrm{T}_{0.90}=\mathrm{T}_{0.95}-\mathrm{T}_{0.05}
$$

where $T_{0.90}$ is the SMD and $T_{0.95}$ and $T_{0.05}$ are the time elapsed at the $95 \%$ and $5 \%$ of the Husid diagram, respectively.

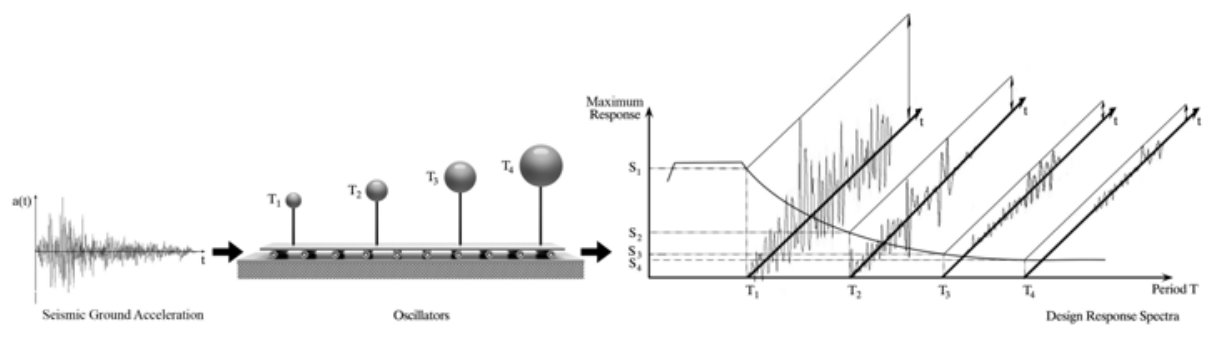

Fig. 2. Concept of the earthquake response spectrum.

\section{Overview of the Proposed Method}

According to the proposed methodology, the original signal is subjected to the HHT so as to obtain the $\mathrm{n}$ amplitude and frequency components. The frequency components of the SMD are submitted to a smoothing procedure and addition of random Gaussian noise. The amplitude components of the SMD are also modified. The artificially generated accelerogram $\operatorname{AGA}(x, t)$ is derived by reconstructing the seismic signal from the new modified instantaneous frequency $\omega_{\mathrm{jNew}}$ and amplitude $\mathrm{a}_{\mathrm{jNew}}$ components:

$$
\operatorname{AGA}(x, t)=\operatorname{Re} \sum_{j=1}^{n}\left(a_{j N e w}(t)\right) e^{j \int \omega_{j N e w}(t) d t}
$$

Each new amplitude component is given by: 


$$
\mathrm{a}_{\mathrm{jNew}}(\mathrm{t})=\mathrm{x}_{\mathrm{k}} \mathrm{a}_{\mathrm{jOld}}(\mathrm{t}), \mathrm{k}=1,2, \ldots, \mathrm{n}
$$

where, $\mathrm{n}$ is the number of extracted IMFs of the initial seismic signal, $\mathrm{x}$ is a vector containing $\mathrm{n}$ scaling parameters of values randomly distributed in the interval [0.81.3 ] and $\mathrm{a}_{\text {jOld }}(\mathrm{t})$ is the initial amplitude value at time $\mathrm{t}$.

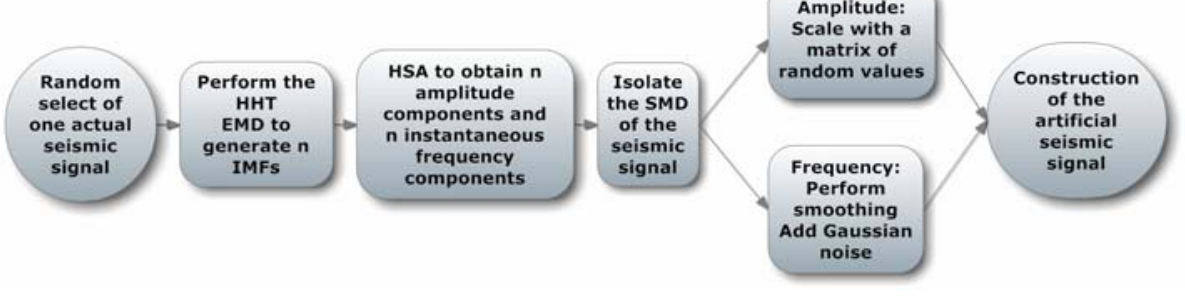

Fig. 3. Block diagram of the proposed method.
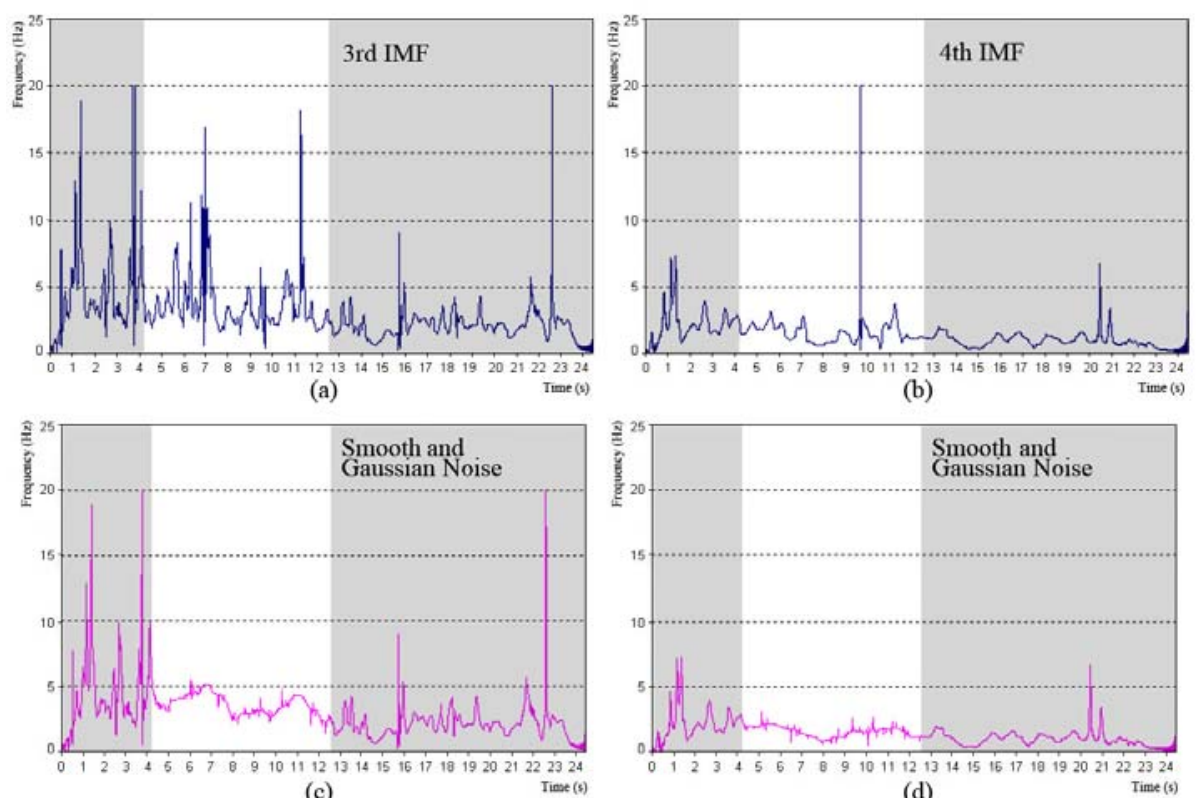

(d)

Fig. 4. (a) The 3rd and (b) 4th IMF of Victoria, Mexico time history record after HSA and (c), (d) after smoothing and addition of Gaussian noise.

The new frequency content is obtained after a two step procedure performed to the frequency components of the natural seismic signal extracted from the EMD. This procedure is applied only to the IMFs that have in the SMD, mean frequency value lower than $5 \mathrm{~Hz}$. This usually occurs after the third IMF and above. The rest of the 
IMFs remain unaffected. The response spectrum acceleration is determined in period range $0.2 \mathrm{~s}$ to $4 \mathrm{~s}(0.25 \mathrm{~Hz}$ to $5 \mathrm{~Hz})$. This range covers the majority of low-, mid- and high-buildings [12]. The first three IMFs are of high frequency, thus of low eigenperiod, so there is no meaning of changing them as they do not contribute to the approximation of the spectrum at the eigenperiods of our interest.

The first step of the procedure employs a smoothing process to the SMD of the appropriate frequency IMFs by utilizing a moving average filter. At a second stage, Gaussian noise is added to create new frequency components that could resemble to the frequency components that were derived from the initial signal. Figure 3 shows the block diagram of the proposed method.

Figures 4(a) and 4(b) show two frequency components of the earthquake in Victoria Mexico. The smoothing and addition of Gaussian noise are performed to the SMD of the earthquake signal and the new components are generated and depicted in Figures 4(c) and 4(d). For the specific earthquake signal the total duration is $24.44 \mathrm{~s}$ while the strong motion duration is between $4.15 \mathrm{~s}$ and $12.67 \mathrm{~s}$.

\section{$5 \quad$ Empirical Results}

The experimental results presented in this section include a comparison of the proposed method with similar state of the art techniques that are widely used for generating artificial spectrum-compatible accelerograms. Database, numerical results and system setup used in the validation process are described in the following sections.

\subsection{Experimental Setup}

In order to assess the performance of the proposed method, an experimental comparison is performed with respect to two other supervised approaches, invoked by the programs SIMQKE [7] and SeismoArtif [9]. SIMQKE is based on Gasparini and Vanmarche algorithm [6]. It estimates a power spectral density function from a specific response spectrum and generates the amplitudes of sinusoidal signals that have phase angles randomly distributed between 0 and $2 \pi$. The SeismoArtif, provides the Synthetic Accelerogram Generation and Adjustment method, based on Hallodorson and Papageorgiou algorithm [8]. From a synthetic accelerogram simulated by the user, the spectrum-compatible artificial accelerogram is defined by adapting its frequency content using the Fourier Transform.

The Root Mean Square Error (RMSE) between the response spectrum of the generated accelerogram and the spectrum of the natural accelerogram is calculated in all experiments:

$$
\mathrm{RMSE}=\sqrt{\frac{1}{\mathrm{~N}} \sum_{\mathrm{j}=1}^{\mathrm{n}}\left(\mathrm{SA}_{\text {generated }}-\mathrm{SA}_{\text {target }}\right)^{2}}
$$


where, $\mathrm{N}$ is the number of samples. The calculation of the RMSE is utilized for the numerical validation of the compatibility between the response spectra of the original and generated seismic accelerograms.

\subsection{Performance Evaluation}

Table 1 includes all information regarding the seismic events [13], that are selected to test the method, and the values of RMSE for the proposed method (PM), the SIMQKE (M1) and the SeismoArtif (M2).

Table 1. Numerical results of the method for 20 seismic events.

\begin{tabular}{|c|c|c|c|c|c|c|}
\hline it & $\mathbf{y}$ & ate & Sta & $\begin{array}{c}\text { RMSE } \\
\text { PM }\end{array}$ & $\begin{array}{c}\text { RMSE } \\
\text { M1 }\end{array}$ & $\begin{array}{c}\text { RMSE } \\
\text { M2 }\end{array}$ \\
\hline akes & S.A. & $05 / 27 / 80$ & 00 & $1.80 \cdot 10^{-2}$ & $1.46 \cdot 10^{-2}$ & $5.09 \cdot 10^{-2}$ \\
\hline Dinar & Turkey & $01 / 10 / 95$ & $/ 090$ & $4.94 \cdot 10^{-2}$ & $2.45 \cdot 10^{-2}$ & $4.89 \cdot 10^{-2}$ \\
\hline Victor & Mexico & $06 / 09 / 80$ & Station 6604 / 045 & $2.04 \cdot 10^{-2}$ & $3.08 \cdot 10^{-2}$ & $3.43 \cdot 10^{-2}$ \\
\hline Gazli & Uzbekistan & $05 / 17 / 76$ & $\mathrm{kyr} / 000$ & $3.79 \cdot 10^{-2}$ & $1.38 \cdot 10^{-2}$ & $3.60 \cdot 10^{-2}$ \\
\hline Tabas & Iran & $09 / 16 / 78$ & abas / LN & $9.12 \cdot 10^{-2}$ & $1.17 \cdot 10^{-1}$ & $7.81 \cdot 10^{-2}$ \\
\hline Spitak & Armenia & $12 / 07 / 88$ & 000 & $1.06 \cdot 10^{-2}$ & 1.3 & $9 \cdot 10^{-2}$ \\
\hline Mor & & $04 / 24 / 84$ & & 8.8 & 3.8 & $1.52 \cdot 10^{-2}$ \\
\hline Patra & Greece & $07 / 14 / 93$ & $1 / \mathrm{NS}$ & $5.05 \cdot 10^{-2}$ & $1.31 \cdot 10^{-1}$ & $5.83 \cdot 10^{-2}$ \\
\hline Pyrgos & Greece & $03 / 26 / 93$ & / NS & 4.0 & 5.3 & $7.28 \cdot 10^{-2}$ \\
\hline & U.S.A. & $10 / 18 / 89$ & $\mathrm{uz} / \mathrm{EW}$ & $2.60 \cdot 10^{-2}$ & 4.96 & $3.46 \cdot 10^{-2}$ \\
\hline Big 1 & U.S.A. & $06 / 28 / 92$ & Lake-Civic Center / 270 & $2.94 \cdot 10^{-2}$ & $2.55 \cdot 10^{-2}$ & $5.29 \cdot 10^{-2}$ \\
\hline Dinar & & $01 / 1$ & & $2.29 \cdot 10^{-4}$ & $3.10 \cdot 10^{-4}$ & $1.49 \cdot 10^{-2}$ \\
\hline Erzican & & $03 / 13 / 92$ & & $1.57 \cdot 10^{-2}$ & $2.66 \cdot 10^{-2}$ & $3.53 \cdot 10^{-2}$ \\
\hline Friuli & ly & $05 / 06 / 76$ & 270 & $1.43 \cdot 10^{-3}$ & 1.5 & $1.10 \cdot 10^{-2}$ \\
\hline Imper & U.S.A. & $10 / 15 / 79$ & Bonds Corner / 230 & $5.68 \cdot 10^{-3}$ & $4.56 \cdot 10^{-3}$ & $3.25 \cdot 10^{-2}$ \\
\hline Kobe & & $01 / 16 / 95$ & & $7.17 \cdot 10^{-3}$ & $3.31 \cdot 10^{-3}$ & $3.16 \cdot 10^{-2}$ \\
\hline Loma Prieta & & $10 / 18 / 89$ & Apeel 10 Skyline / 090 & $9.47 \cdot 10^{-3}$ & $2.52 \cdot 10^{-2}$ & $7.48 \cdot 10^{-2}$ \\
\hline Mammoth Lakes & U.S.A. & $05 / 27 / 80$ & Convict Creek / 090 & $1.20 \cdot 10^{-2}$ & $9.88 \cdot 10^{-3}$ & $2.24 \cdot 10^{-2}$ \\
\hline Northridge & U.S.A. & $03 / 20 / 94$ & Anacapa Island / 270 & $1.24 \cdot 10^{-3}$ & $3.97 \cdot 10^{-4}$ & $2.53 \cdot 10^{-2}$ \\
\hline San Fransisco & U.S.A. & $03 / 22 / 57$ & Golden Gate / 100 & $4.52 \cdot 10^{-3}$ & $8.96 \cdot 10^{-3}$ & $2.07 \cdot 10^{-2}$ \\
\hline
\end{tabular}

It can be observed that all RMSE values are very close in all methods. However, the PM leads to spectrum compatible artificial seismic accelerograms with lower RMSE in most experiments. The PM can be directly compared with the two wellknown procedures and be advantageous since is not an iterative method. The RMSE calculated for the two standard methods is the average of ten measurements derived from different number of iteration $(1,3,5,7,9,11,13,15,20$ and 25) while the RMSE for the PM is the average of ten measurements of only one iteration each. In Table 2 it is recorded the RMSE for six experiments with the PM, and the number of iterations that need both M1 and M2 in order to obtain approximately the same range 
of values for the RMSE. The PM performs one iteration to achieve that range of RMSE, while at least three iterations are required for M1 and over five for M2.

Table 2. RMSE toward number of iterations for the proposed method, SIMQKE and SeismoArtif for six seismic events.

\begin{tabular}{lc|cc}
\hline $\begin{array}{c}\text { Seismic event } \\
\text { (Station) }\end{array}$ & Method & RMSE & $\begin{array}{c}\text { Number of } \\
\text { iterations }\end{array}$ \\
\hline Mammoth Lakes & PM & $1.80 \cdot 10^{-2}$ & 1 \\
(FIS) & M1 & $5.76 \cdot 10^{-2}$ & 11 \\
\hline Dinar & P2 & $1.74 \cdot 10^{-2}$ & 19 \\
(Dinar) & M1 & $4.94 \cdot 10^{-2}$ & 1 \\
& M2 & $4.60 \cdot 10^{-2}$ & 3 \\
Victoria & PM & $2.04 \cdot 10^{-2}$ & 7 \\
(Station 6604) & M1 & $2.25 \cdot 10^{-2}$ & 1 \\
& M2 & $2.77 \cdot 10^{-2}$ & 25 \\
Gazli & P.M & $3.79 \cdot 10^{-2}$ & 1 \\
(Karakyr) & M1 & $4.12 \cdot 10^{-2}$ & 3 \\
& M2 & $3.87 \cdot 10^{-2}$ & 11 \\
\hline \multirow{2}{*}{ Tabas } & PM & $9.12 \cdot 10^{-2}$ & 1 \\
(Tabas) & M1 & $9.21 \cdot 10^{-2}$ & 7 \\
\hline Spitak & M2 & $9.27 \cdot 10^{-2}$ & 5 \\
(Gukasian) & PM & $1.06 \cdot 10^{-2}$ & 1 \\
& M1 & $1.04 \cdot 10^{-2}$ & 5 \\
\hline & M2 & $1.08 \cdot 10^{-2}$ & 25 \\
\hline
\end{tabular}

Figure 5 shows the natural seismic signal of Victoria, and the generated seismic signal with the PM, M1 and M2. The artificial signals generated by the two programs and the PM are of the same duration and compatible with the same target spectrum. SIMQKE generates artificial signals by varying the random phase angles of the sinusoidal signals and all generated signals are restricted to have a uniform shape that is provided by a predetermined envelop. In SeismoArtif, the generation of the synthetic accelerogram starts from a Gaussian white noise that is multiplied by the envelop shape suggested by Saragoni and Hart [14]. Both methods derive accelerograms that follow predetermined envelop shapes, thus, accelerograms generated with either of the two methods tend to resemble among them.

In order to demonstrate the ability of the PM to generate multiple different accelerograms, the standard deviation (SD) is used as a metric. Figure 6 demonstrates the SD between ten artificially generated seismic signals with the PM and the mean of them, starting from the natural record of Victoria, in contrast to the SD of ten artificially generated seismic signals with M1 and M2 and the mean of them. During the SMD of the signal, the SD is greater with the PM rather than with M1 and M2. 


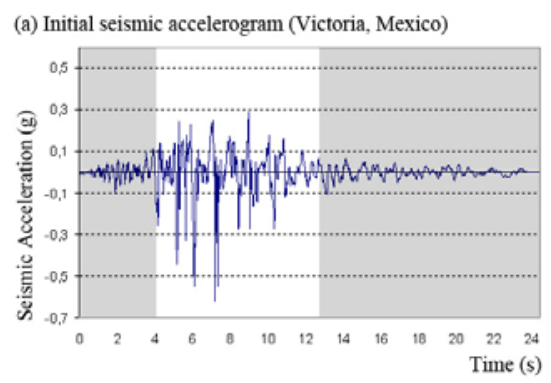

(c) Artificial seismic accelerogram (SIMQKE-Ml: 25 iterations)

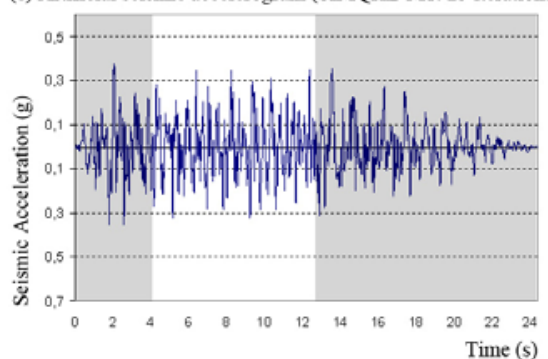

(b) Artificial seismic accelerogram (PM)

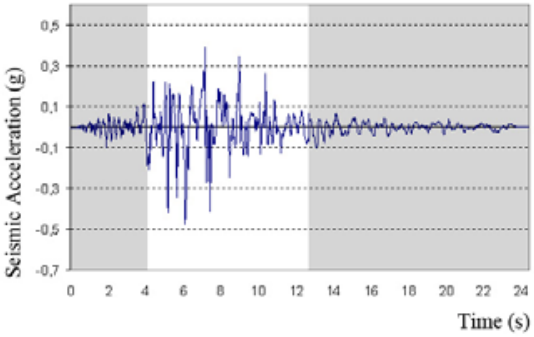

(d) Artificial seismic accelerogram (SeismoArtif-M2: 25 iterations)

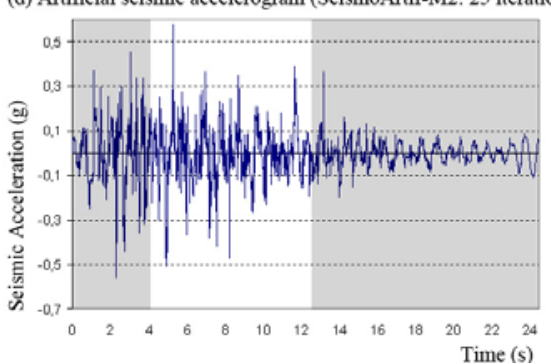

Fig. 5. (a) Victoria, Mexico time history record (b) artificially generated accelerogram with the PM (c) artificial seismic signal derived from M1 (d) artificial seismic signal derived from M2.

Figure 7(a) shows the target spectrum and the mean spectra of the proposed and the two established methods evaluated with the programs SIMQKE and SeismoArtif. All spectra are compatible with the target spectrum and have slight differences (Table 1).

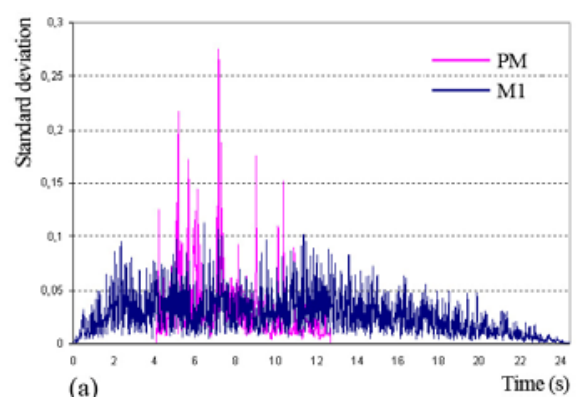

(a)

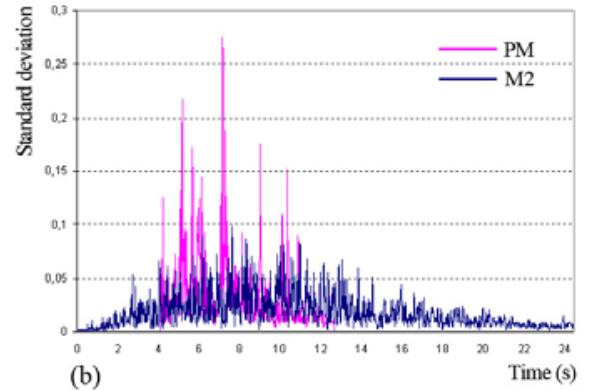

(b)

Fig. 6. Standard deviation between ten artificially generated signals (compatible with the Victoria spectrum) and the mean of them, using (a) the PM and SIMQKE (M1) (b) the PM and SeismoArtif (M2).

The mean spectrum is the average of ten artificially generated signals. The mean spectrum of the PM is evaluated from ten measurements with different amount of smoothing by varying the span of the moving average filter and adding more noise to 
the components. The mean spectrum of M1 and M2 stem from ten measurements with different number of iterations.

Finally, all generated artificial seismic accelerograms with the PM follow the restrictions of Eurocode 8 [15]. According to Eurocode 8, in the range of periods between $0.2 \mathrm{~T}_{1}$ and $2 \mathrm{~T}_{1}\left(\mathrm{~T}_{1}\right.$ is the fundamental period of the structure) no value of the mean 5\% damping elastic spectrum, calculated from all time histories, should be less than $90 \%$ of the corresponding value of the $5 \%$ damping elastic response spectrum. In Figure 7 (b) are demonstrated the $90 \%$ of the target response spectrum and the mean spectra of four artificially generated seismic signals with the PM.

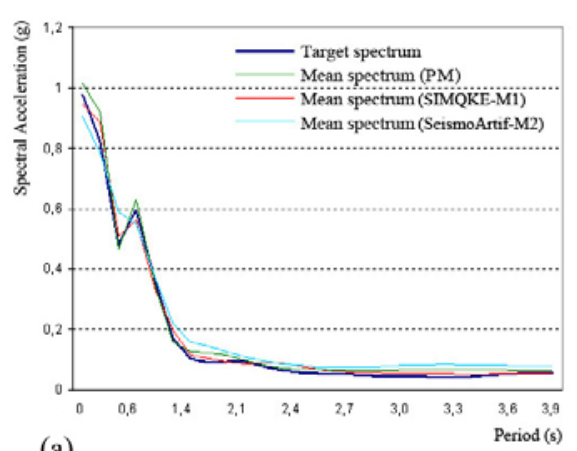

(a)

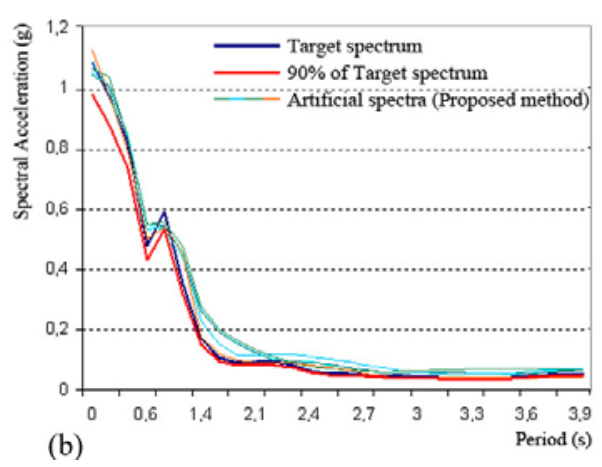

(b)

Fig. 7. (a) Target spectrum and mean spectra of the PM, M1 and M2 (b) target spectrum, spectra of four artificial generated signals with the PM and $90 \%$ of the target spectrum.

\section{Conclusions}

Artificial spectrum-compatible accelerograms are used instead of natural acceleration records for the dynamic analysis of many critical structures for sites with no strong ground motion data. A new method for generating spectrum-compatible seismic accelerograms based on the HHT is proposed. One randomly selected seismic event is decomposed in amplitude and frequency components. The amplitude components of the SMD are scaled and the appropriate frequency components of the SMD are subjected to smoothing and addition of Gaussian noise.

The PM is flexible, since it requires only one seismic event, that can be from any region globally and of any intensity. This option makes the algorithm faster without affecting its accuracy by choosing seismic accelerograms with a definite number of points. Moreover, in order to analyze the non-stationary data only a small number of IMFs is required.

Comparison with two other state of art methods, one based on Gasparini and Vanmarcke algorithm (calculated by SIMQKE) and the other based on Hallodorson and Papageorgiou algorithm (calculated by SeismoArtif), has shown the satisfactory performance of the PM. The introduction of SD revealed that the PM can derive multiple 
different accelerograms. The proposed method is not an iterative method and all generated signals follow the restrictions of the Eurocode 8.

\section{$7 \quad$ References}

1. Carballo, J. E.: Probabilistic seismic demand analysis: spectrum matching and design. Doctoral dissertation, Stanford University, Stanford, California, USA (2000)

2. Huang, N. E., Shen, Z., Long, S. R. et al.: The empirical mode decomposition and the Hilbert spectrum for nonlinear and non-stationary time series analysis. Proceedings of the Royal Society A, 454, pp. 903--995, London (1998)

3. Alvanitopoulos, P., Andreadis, I. and Elenas A.: Interdependence between seismic parameters and damage indicies based on Hilbert-Huang Transform. IOP Journal of Measurements Science and Technology, 21, 1--14 (2010)

4. Ni S., Xie W. and Pandey M.: Application of Hilbert-Huang transform in generating spectrum-compatible earthquake time histories, ISRN Signal Processing, Article ID 563678 (2011)

5. Vrochidou, E., Alvanitopoulos, P., Andreadis, I. and Elenas A.: Correlation between seismic intensity parameters of HHT-based synthetic seismic accelerograms and damage indices of buildings, 8th IFIP Int. Conf. on Artificial Intelligence \& Applications (AIAI), Chalkidiki Greece, September, 1--6 (2012)

6. Gasparini, D. and Vanmarcke, E. H.: SIMQKE - A program for artificial motion generation, user's manual and documentation. Publication No R76-4, Massachusetts Institute of Technology, Civil Engineering Department, Cambridge Massachusetts (1976)

7. Gelfi, P.: SIMQKE GR version 2.7. University of Bescia, http: // dicata.ing.unibs.it /gelfi/software/simqke/simqke_gr.htm, Italy (2012)

8. Halldorsson, B. and Papageorgiou, A. S.: Calibration of the specific barrier model to earthquake of different tectonic regions. Bulletin of the Seismological Society of America, 95, 1276--1300 (2005)

9. Computer program SeismoArtif, version 1.0.0.: 'SeismoArtif's help system-(C) 2002-2012', Seismosoft Ltd

10. Trifunac, M. and Brady, A.G.: A study on the duration of strong earthquake ground motion. Bulletin of the Seismological Society of America, 65, 581-- 626 (1975)

11. Husid, R.: Analisis de terremoros: analisis general. Rev. IDIEM, 8, 21--42 (1969)

12. Bommer, J. J. and Elnashai, A. S.: Displacement spectra for seismic design. Journal of Earthquake Engineering, 3, 1--32 (1999)

13. PEER Ground Motion Database, Pacific Earthquake Engineering Research Center, http: // peer.berkeley.edu/peer_ground motion_database

14. Saragoni, G. R. and Hart, G. C.: Simulation of artificial earthquakes. Earthquake Engineering and Structural Dynamics, 219--267 (1974)

15. EC8, Eurocode 8: Design of Structures for Earthquake Resistance- Part 1: General Rules, Seismic Actions, and Rules for Buildings. European Committee for Standardization, Brussels, Belgium (2004) 